\title{
Chromosomal imbalances identified by comparative genomic hybridization in sporadic parathyroid adenomas
}

\author{
Juan Luis García, Juan C Tardío ${ }^{1}$, Norma Carmen Gutiérrez, María Belén González, José Ramón Polo², \\ Jesús María Hernández and Javier Menárguez ${ }^{3}$ \\ Department of Haematology, Hospital Universitario de Salamanca and Centro de Investigación del Cáncer, Universidad de Salamanca-CSIC \\ Salamanca, Spain, ${ }^{1}$ Department of Pathology, Hospital El Escorial, Madrid, Spain, and Departments of ${ }^{2}$ Surgery and ${ }^{3}$ Pathology, Hospital General \\ Universitario Gregorio Marañón, Madrid, Spain
}

(Correspondence should be addressed to J Menárguez, Department of Pathology, Hospital General Universitario Gregorio Marañón, Dr Esquerdo 46, 28007 Madrid, Spain; Email: anatomiap@anat.hggm.es)

\begin{abstract}
Objective: To identify chromosomal gains and losses in sporadic parathyroid adenomas (PAs). Methods: Fourteen sporadic PAs were studied by comparative genomic hybridization (CGH). Results: The fourteen studied PAs showed chromosomal imbalances. All cases except one exhibited two or more abnormalities. Chromosomal gains were found in all cases, and three cases (21\%) also presented chromosomal losses. Genomic amplification was not observed. Chromosome 9 was involved in ten cases. Recurrent genetic gain was found on 9p22-24 and on 9q34, each in 6 of 14 cases (43\%). Other recurrent gains included Xq26 in 6 PAs (43\%) and 4q21-28 and 8 p22-23, each in 4 of 14 cases (29\%). Regions of recurrent genetic loss involved whole chromosome 11 and $20 q 12-13$, each in 2 of 14 cases (14\%).

Conclusions: Our findings show chromosomal imbalances in all sporadic PAs studied by CGH, partly confirming previous reports, with the exception that we observed more chromosomal gains than losses. Several regions (9p22-24, 9q34, Xq26, 4q21-28, and 8p22-23) probably deserve further investigation in order to discard the presence of genes involved in parathyroid tumorigenesis.
\end{abstract}

European Journal of Endocrinology 146 209-213

\section{Introduction}

Primary hyperparathyroidism is a common endocrine disorder characterized by an excessive production of parathyroid (PT) hormone (PTH). Sporadic PT adenomas (PAs) are currently the cause of primary hyperparathyroidism in the vast majority of the patients. PAs are benign clonal proliferations of PT chief cells (1).

Two genetic aberrations are known to be implicated in the pathogenesis of sporadic PAs: (i) cyclin D1 overexpression in a small subset of these tumors, as a result of rearrangement of the cyclin D1/PRAD1 oncogene, located on chromosome 11q13, with the PTH gene on 11p15 (2-4), and (ii) multiple endocrine neoplasia type 1 (MEN1) tumor suppressor gene (on 11q13) inactivation by allelic loss and somatic mutation of the remaining allele (5-9) in about $20-30 \%$ of cases. Lowered levels of calcium receptor messenger RNA detected by in situ hybridization (10), $\mathrm{t}(1 ; 5)(11)$, and other genetic alterations, such as loss of heterozygosity (LOH) by microsatellite analysis, involving chromosomes $1 \mathrm{p}(8$, 12-15), 3q (16), 6q (17), 9p (18), 11p (19) and 15q (17) have also been reported in a variable percentage of
PAs. Allelic losses of $13 \mathrm{q}$ involving the $\mathrm{Rb}$ and the BRCA2 genes have been reported in PAs with aggressive clinical and histopathological features (20). However, the genetic bases of the majority of PAs are unknown.

Comparative genomic hybridization $(\mathrm{CGH})$ is a double color hybridization procedure which provides, in a single experiment, a general view of genomic imbalances, including partial or complete trisomies, monosomies or amplifications within the tumor genome (21). This technique can be used to identify previously unexpected genetic abnormalities. Several groups have studied chromosomal changes by CGH in different solid tumors, but limited information concerning sporadic PAs is presently available $(22-25)$. We have applied CGH to identify genomic imbalances in 14 patients with PAs.

\section{Materials and methods}

Tumor specimens from 14 patients with sporadic PAs were included in the study. All samples were studied at diagnosis. 
Table 1 Comparative genomic hybridization findings in sporadic parathyroid adenomas.

\begin{tabular}{|c|c|c|c|}
\hline Case & Age (years)/Sex & Gains & Losses \\
\hline 1 & $72 / \mathrm{F}$ & $3 p 24-p 26,9 p 22-p 24$ & \\
\hline 2 & $60 / F$ & $6 p 11-p 25$ & $\begin{array}{l}6 q 12-q 27,9 p 24-q 33,11,15, \\
18 q 12-q 22,20\end{array}$ \\
\hline 3 & $64 / \mathrm{M}$ & $\begin{array}{l}1 q 41-q 43,3 q 27-q 29,4 q 34-q \text { ter, 6q27-qter, 8p22-p23, } \\
9 p 22-p 24,10 p 14-p 15,11 q 24-q 25 \\
14 q 32-q \text { ter, 16q23-q24, 17q24-q25 } \\
19 q 13,20 q 13,21 q 22, \text { Xq26-q27 }\end{array}$ & \\
\hline 4 & $75 / F$ & $\begin{array}{l}2 p 24-p 25,3 q 21-q 24,4 q 21-q 28,7 p 15-p 22,7 q 35,9 q 33-q 34, \\
14 q 32-q t e r, 18 q 22-q 23, x\end{array}$ & \\
\hline 5 & $67 / F$ & $\begin{array}{l}\text { 1p32-p36, 9q32-q34, 11q32, 12q24, 14q31-q32, 17q24-q25, } \\
19 p 12-p 13, \text { Xq26-q28 }\end{array}$ & \\
\hline 6 & $68 / F$ & $\begin{array}{l}2 q 22-q 31,4 q 13-q 31,6 q 16-q 22,10 q 25-q 26,13 q 22-q 32 \\
15 q 25-q 26,18 q 22-q 23\end{array}$ & \\
\hline 7 & $75 / F$ & $1 q 41-q 43,9 q 34-q t e r, X q 12-q 26$ & \\
\hline 8 & $68 / F$ & $1 q 24-q 31,19 q 13,20 q 12-q 13,22 q, X q 12-q 28$ & \\
\hline 9 & $52 / \mathrm{F}$ & $2 q 22-q 31,4 q 13-q 31,5 q 12-q 15,13 q 22-q 32, \times q 13-q 27$ & \\
\hline 10 & $78 / \mathrm{F}$ & 9 & \\
\hline 11 & $55 / F$ & 8,9 & \\
\hline 12 & $50 / \mathrm{F}$ & $1,6 \mathrm{p} 21-\mathrm{p} 23,7,8,9,10,12,16,20 \mathrm{q} 13$ & $11,13,19 \mathrm{p} 12-\mathrm{p} 13$ \\
\hline 13 & $52 / F$ & $1 p 22-p 32,3 q 21-q 26,4,6 q 12-q 23,8,11 q 14-q 22$ & \\
\hline 14 & $63 / F$ & $\begin{array}{l}4 q 34,5 q 33-q 35,9 p 22-p 24,10 q 25-q 26,12 q 23-q 25 \\
13 q 33-q 34,18 q 22-q 23\end{array}$ & $20 q 12-q 13$ \\
\hline
\end{tabular}

Tumor DNA was isolated from PAs. Reference DNA was obtained from peripheral blood lymphocytes of healthy donors (same sex as patients). Phenolchloroform was used for DNA extraction according to standard procedures (26). CGH analysis was performed according to the method described by Lichter and Ried (27). Briefly, tumor DNA (test DNA) was labeled with biotin-16-dUTP (Boehringer Mannheim, Mannheim, Germany) and normal DNA (reference DNA) was labeled with digoxigenin-11-dUTP (Boehringer Mannheim) by a standard nick translation reaction. The size of the nick-translated fragments ranged from 300 to $1000 \mathrm{bp}$. Equal amounts $(1 \mu \mathrm{g})$ of labeled tumor and normal DNAs, and $70 \mu \mathrm{g}$ unlabeled human Cot-1 DNA (GIBCO/BRL, Gaithersburg, MD, USA) were cohybridized to slides with human metaphase chromosome spreads prepared from phytohemagglutinin-stimulated lymphocytes from normal individuals. After hybridization for 1 to 2 days in a moist chamber at $37^{\circ} \mathrm{C}$, post-hybridization washes were performed to a stringency of $0.1 \times \mathrm{SSC}$ at $42^{\circ} \mathrm{C}$. Tumor and normal DNA were detected by avidin-fluorescein isothiocyanate (FITC) and rhodamine-conjugated anti-digoxigenin respectively. The slides were counterstained with 4,6-diamidino-2-phenylindole (DAPI) and mounted with an antifade solution. Image acquisition was performed with an epifluorescence microscope (Olympus BX60) equipped with a cooled charge-coupled device (CCD) camera. Calculation of the tumor DNA to normal DNA fluorescent ratios along the length of each chromosome was performed by means of an automated CGH software package (Cytovision, Applied Imaging, Sunderland, UK). Ratio values obtained from at least 10 metaphase cells for each case were averaged. Ratio values above 1.25 and below 0.75 were considered to represent chromosomal gain and loss respectively. Over-representations were defined as high-level amplifications when the profiles exceeded the cut-off value of 1.5. Chromosomal gains exceeding 1.5 involving the whole chromosome or large areas of a chromosomal arm were not considered as high-level DNA amplification. Negative control experiments were performed using differentially labeled male versus male and female versus female DNA. Additional control experiments included the interchange of the digoxigenin-dUTP and biotindUTP labels between normal and tumor DNA.

\section{Results}

The patients were thirteen women and one man, and their ages ranged from 50 to 78 years (mean 64.2; median 65.5) (Table 1). Diagnosis of PAs relied upon clinical, surgical and pathological findings. Histologically, all cases were conventional PAs.

The fourteen studied PAs showed chromosomal imbalances, including losses or gains of whole or part of chromosomes. All cases except one exhibited two or more abnormalities (Table 1). Chromosomal gains were observed in all cases. Three of them (21\%) presented chromosomal losses. No genomic amplification was observed. The summary of gains and losses is shown in Fig. 1.

Chromosome 9 was involved in ten cases. Recurrent genetic gain was found on 9p22-24 and on 9q34, each in 6 of 14 cases $(43 \%)$. Other recurrent gains involved chromosome $\mathrm{X}$ in 6 PAs (43\%) with a consensus region 
on Xq26; $4 \mathrm{q}$ with a consensus region on $4 \mathrm{q} 21-28$ and chromosome 8 with a consensus region on 8 p22-23, each in 4 of 14 cases $(29 \%)$; as well as $1 p$ with a consensus region on $1 \mathrm{p} 32,1 \mathrm{q} 41-43,4 \mathrm{q} 34,10 \mathrm{q} 25-26$, $12 \mathrm{q}$ with a consensus region on $12 \mathrm{q} 24,14 \mathrm{q}$ with a consensus region on $14 \mathrm{q} 32,18 \mathrm{q} 22-23$, and $20 \mathrm{q}$ with a consensus region on 20q13, each in 3 of 14 cases $(21 \%)$; and $2 \mathrm{q} 22-31$, $3 \mathrm{q}$ with a consensus region on $3 \mathrm{q} 21-24,6 \mathrm{p}$ with a consensus region on $6 \mathrm{p} 21-23,6 \mathrm{q}$ with a consensus region on $6 \mathrm{q} 16-22$, $7 \mathrm{p} 15-22,7 \mathrm{q} 35,10 \mathrm{p} 14-15,13 \mathrm{q}$ with a consensus region on 13q22-32, 16q23-24, 17q24-25 and $19 \mathrm{q} 13$, each in 2 of 14 cases $(14 \%)$. Gains of 2 p2425, 3p24-26, 5q12-15, 5q33-35, 11q14-22, $11 \mathrm{q} 24-25,11 \mathrm{q} 32,13 \mathrm{q} 33-34,15 \mathrm{q} 25-26,19 \mathrm{p} 12-$ $13,21 \mathrm{q} 22$ and $22 \mathrm{q}$ were each found in one of fourteen cases $(7 \%)$ (Table 1$)$.

Regions of recurrent genetic loss included whole chromosome 11 and 20q12-13, each in two of fourteen cases $(14 \%)$. Losses at $6 \mathrm{q} 12-27,9 \mathrm{p} 24-\mathrm{q} 33,13$, $15,18 \mathrm{q} 12-22$ and $19 \mathrm{p} 12-13$ were each found in one of fourteen cases $(7 \%)$ (Table 1$)$.
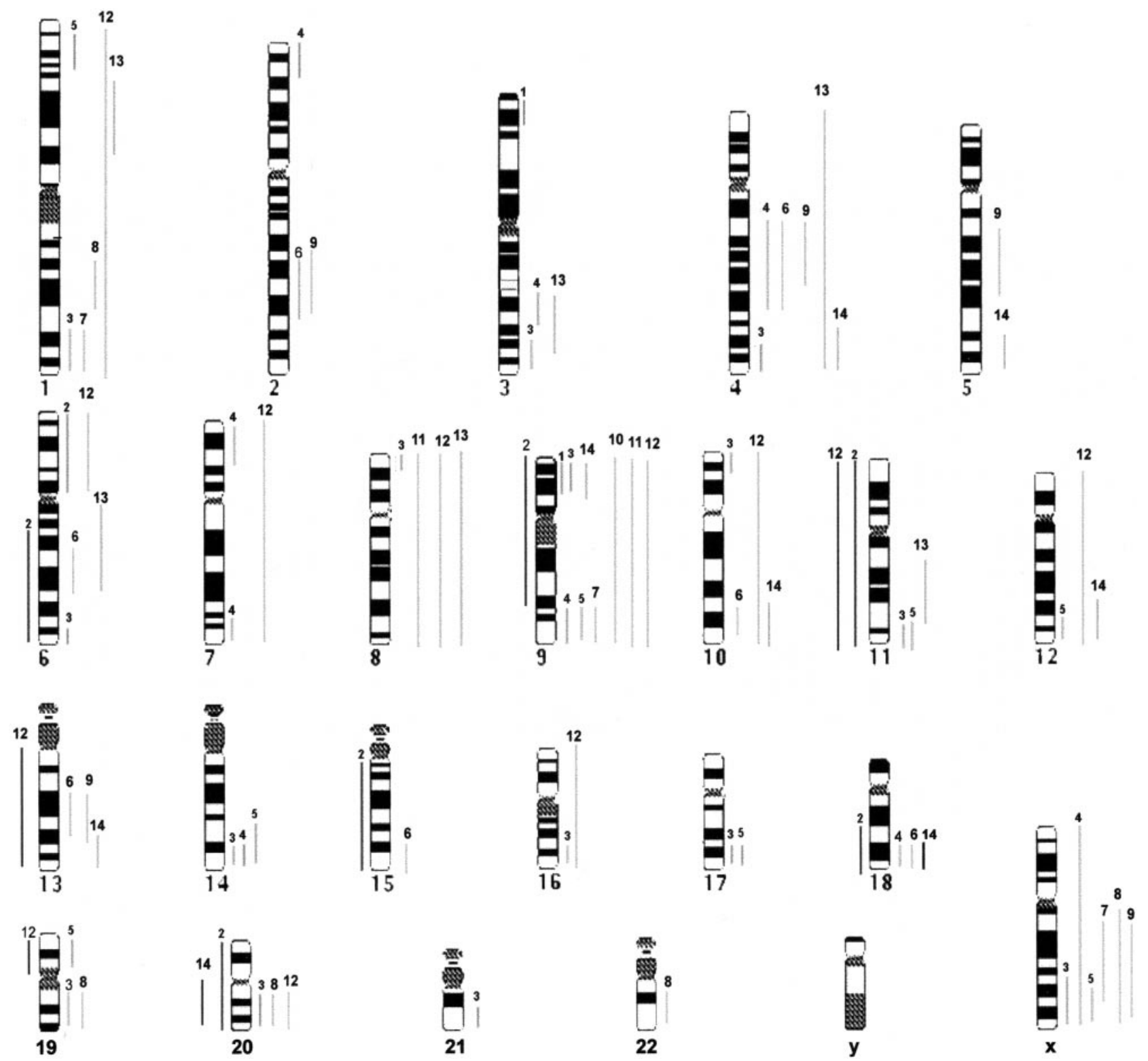

Figure 1 Summary of genetic aberrations found by comparative genomic hybridization in sporadic parathyroid adenomas. Gains are represented by lines at the right of the chromosomes and losses by lines at the left. Line lengths correspond to gains or losses of genetic material. Numbers on top of the lines represent case identification. 


\section{Discussion}

We have found chromosomal imbalances in all PAs studied by CGH, with multiple abnormalities in most cases. Genetic gains were more frequent than losses in our series. Significant recurrent findings were genetic gains on 9p22-24, 9q34 and Xq26 in $43 \%$ of cases each, and on 4q21-28 and 8p22-23 in 29\% of cases each. Some of these findings have previously been reported in PT neoplasms studied by CGH analysis, suggesting putative regions for oncogenes implicated in PT tumorigenesis. Chromosomal gain on $9 \mathrm{p}$ has been reported by Agarwal et al. (22) in one of 10 sporadic PAs (10\%). Farnebo et al. (24) observed gain of whole chromosomes X and 4, each in one of 26 sporadic PAs (4\%). Palanisamy et al. (23) found gain of whole chromosome 8 in one of the 53 sporadic PAs (2\%) and Hemmer et al. (25) reported high-level amplification on chromosome 8 at a region involving 8 p22 in one of 16 PAs $(6 \%)$. Genetic gain of $9 \mathrm{q}$, on a region including $9 q 34$, has been reported in 7 of 29 PT carcinomas (24\%) (28), and gain of whole chromosome 4 in 2 of 10 PT carcinomas (20\%) (22). We have specifically investigated the presence of potential correlations between CGH findings and different clinical parameters, macroscopical and histological features and immunohistochemical expression of several proliferation markers and cell cycle proteins $(29,30)$ in our series. We have not been able to demonstrate any correlation (results not shown).

Four previously published reports have studied sporadic PAs by CGH $(22-25)$. They found chromosomal imbalances in 62 to $90 \%$ of cases. The high number of genetic alterations detected by this technique in PAs, a benign neoplasm, contrasts with the findings in other types of endocrine tumors where they are correlated to the grade of malignancy (31), suggesting that the oncogenetic mechanisms may not be identical in different endocrine organs. In PAs, genetic losses are predominant. There are two frequent recurrent aberrations common to the four reports: losses on chromosome 11 and on chromosome 15, suggesting the existence of putative tumor suppressor genes implicated in PT tumorigenesis on these chromosomes. Losses on chromosome 11 have been found in 31 to $40 \%$ of cases in these four series. We found loss of chromosome 11 in $14 \%$ of our cases. As a whole, losses involving chromosome 11q have been reported in 39 of 119 sporadic PAs (33\%) studied by CGH in the five published series, including ours. This alteration could be related to MEN1 gene abnormalities found by LOH and somatic mutation in these tumors (6-9). However, in a recent report by Hemmer et al. (25) the common deleted region on 11q was 11q23, with the presence of the two MEN1 alleles at 11q13 confirmed by fluorescent in situ hybridization. Furthermore, CGH frequently shows monosomy or extensive losses on chromosome 11 that include 11p. Two sporadic PAs with 11 p loss that was not accompanied by $11 \mathrm{q}$ loss have been reported $(22,23)$. These findings suggest the existence of additional tumor suppressor genes implicated in PT tumorigenesis on regions of chromosome 11 other than 11q13. LOH for several genes located on chromosome 11p has been reported in primary hyperparathyroidism (19), lending further support to this suggestion. Some known tumor suppressor genes located on 11q23 appear to be implicated in different human neoplasms $(32-34)$, but their potential role in PT tumorigenesis is presently unknown.

Losses on chromosome $15 \mathrm{q}$ have been found in 12 to $30 \%$ of cases in the four previously published series $(22-25)$ and in $7 \%$ of our cases. As a whole, 22 of 119 sporadic PAs (18\%) studied by CGH have shown this aberration. $\mathrm{LOH}$ on $15 \mathrm{q}$ in PAs has been reported previously (17). These findings could suggest the existence of a tumor suppressor gene implicated in PT tumorigenesis located on 15q.

Up to now only a handful of primary PT hyperplasias has been investigated by CGH. Based upon the reported results and in contrast with PAs, PT hyperplasias show scarce chromosomal gains or losses, hindering the establishment of a common profile. The only significant recurrent chromosomal aberration appears to be loss of $11 \mathrm{q}$ in less than $10 \%$ of cases (25).

Only two reports address chromosomal aberrations in PT carcinomas by CGH $(22,28)$. In spite of having only partially overlapping findings, these reports suggest that loss of $1 \mathrm{p}$, present in $40 \%$ of cases, could be a significant feature. This aberration is a less frequent finding in PAs (13\%).

Based upon available evidence, it is not currently possible to pinpoint CGH abnormalities that could: (i) discriminate between PT carcinomas and PAs and (ii) forecast malignant transformation in PAs, otherwise an extremely infrequent event. In addition, as stated above, we have not been able to establish any significant CGH aberration in our series identifying clinical or pathological aggressive PAs.

In conclusion, our findings show chromosomal imbalances in all sporadic PAs studied by CGH, suggesting potential candidate locations for genes implicated in PT tumorigenesis on 9p22-24, 9q34, Xq26, 4q21-28, 8p22-23, 11 and 15q.

\section{Acknowledgements}

This work was partially supported by grants from Spanish FIS (97/230, 00/1089, 00/0008-01). NCG is supported by a grant from the Centro de Investigación del Cáncer (CIC), Universidad de Salamanca-CSIC, Spain.

\section{References}

1 Arnold A, Staunton CE, Kim HG, Gaz RD \& Kronenberg HM. Monoclonality and abnormal PT hormone genes in parathyroid 
adenomas. New England Journal of Medicine $1988 \mathbf{3 1 8}$ 658-662.

2 Arnold A, Kim HG, Gaz RD, Eddy RL, Fukushima Y, Byers MG et al. Molecular cloning and chromosomal mapping of DNA rearranged with the parathyroid hormone gene in a parathyroid adenoma. Journal of Clinical Investigation $1989832034-2040$.

3 Motokura T, Bloom T, Kim HG, Juppner H, Ruderman JV, Kronenberg HM \& Arnold A. A novel cyclin encoded by bcl1-linked candidate oncogene. Nature $1991350512-515$.

4 Rosenberg CL, Kim HG, Shows TB, Kronenberg HM \& Arnold A. Rearrangement and overexpression of D11S287E, a candidate oncogene on chromosome $11 \mathrm{q} 13$ in benign parathyroid tumors. Oncogene $19916449-453$.

5 Iwasaki H. A possible tumor suppressor gene for parathyroid adenomas. International Surgery $19968171-76$.

6 Heppner C, Kester MB, Agarwal SK, Debelenko LV, Emmert-Buck MR, Guru SC et al. Somatic mutation of the MEN1 gene in parathyroid tumors. Nature Genetics 199716 375-378.

7 Karges W, Jostarndt K, Maier S, Flemming A, Weitz M, Wissmann A et al. Multiple endocrine neoplasia type 1 (MEN1) gene mutations in a subset of patients with sporadic and familial primary hyperparathyroidism target the coding sequence but spare the promoter region. Journal of Endocrinology 2000166 $1-9$.

8 Dwight T, Twigg S, Delbridge L, Wong FK, Farnebo F, Richardson AL et al. Loss of heterozygosity in sporadic parathyroid tumours: involvement of chromosome 1 and the MEN1 gene locus in 11q13. Clinical Endocrinology 200053 85-92.

9 Miedlich S, Krohn K, Lamesch P, Muller A \& Paschke R. Frequency of somatic MEN1 gene mutations in monoclonal parathyroid tumours of patients with primary hyperparathyroidism. European Journal of Endocrinology 2000143 47-54.

10 Farnebo F, Enberg U, Grimelius L, Backdahl M, Schalling M, Larsson $\mathrm{C}$ et al. Tumor-specific decreased expression of calcium sensing receptor messenger ribonucleic acid in sporadic primary hyperparathyroidism. Journal of Clinical Endocrinology and Metabolism 199782 3481-3486.

11 Orndal C, Johansson M, Heim S, Mandahl N, Mansson B, Alumets J et al. Parathyroid adenoma with $\mathrm{t}(1 ; 5)(\mathrm{p} 22 ; \mathrm{q} 32)$ as the sole clonal chromosome abnormality. Cancer Genetics and Cytogenetics $199048225-228$.

12 Cryns VL, Yi SM, Tahara H, Gaz RD \& Arnold A. Frequent loss of chromosome arm 1p DNA in parathyroid adenomas. Genes Chromosomes and Cancer $1995139-17$.

13 Tahara H, Smith AP, Gaz RD, Zariwala M, Xiong Y \& Arnold A. Parathyroid tumor suppressor on 1p: analysis of the p18 cyclindependent kinase inhibitor gene as a candidate. Journal of Bone and Mineral Research 199712 1330-1334.

14 Williamson C, Pannett AA, Pang JT, Wooding C, McCarthy M, Sheppard MN et al. Localisation of a gene causing endocrine neoplasia to a $4 \mathrm{cM}$ region on chromosome 1p35-p36. Journal of Medical Genetics 199734 617-619.

15 Shan L, Yang Q, Nakamura Y, Nakamura M, Miyauchi A, Tsujimoto $\mathrm{M}$ et al. Frequent loss of heterozygosity at $1 \mathrm{p} 36.3$ and p73 abnormality in parathyroid adenomas. Modern Pathology $200114273-278$

16 Thompson DB, Samowitz WS, Odelberg S, Davis RK, Szabo J \& Heath H 3rd. Genetic abnormalities in sporadic parathyroid adenomas: loss of heterozygosity for chromosome $3 \mathrm{q}$ markers flanking the calcium receptor locus. Journal of Clinical Endocrinology and Metabolism $1995 \mathbf{8 0} 3377-3380$.

17 Tahara H, Smith AP, Gaz RD, Cryns VL \& Arnold A. Genomic localization of novel candidate tumor suppressor gene loci in human parathyroid adenomas. Cancer Research $1996 \mathbf{5 6}$ 599-605.

18 Tahara H, Smith AP, Gaz RD \& Arnold A. Loss of chromosome arm 9p DNA and analysis of the p16 and p15 cyclin-dependent kinase inhibitor genes in human parathyroid adenomas. Journal of Clinical Endocrinology and Metabolism 199681 3663-3667.

19 Inagaki C, Dousseau M, Pacher N, Sarfati E, Drueke TB \& Gogusev J. Structural analysis of gene marker loci on chromosomes 10 and 11 in primary and secondary uraemic hyperparathyroidism. Nephrology Dialysis and Transplantation 199813 350-357.

20 Pearce SH, Trump D, Wooding C, Sheppard MN, Clayton RN \& Thakker RV. Loss of heterozygosity studies at the retinoblastoma and breast cancer susceptibility (BCRA2) loci in pituitary, parathyroid, pancreatic and carcinoid tumors. Clinical Endocrinology $199645195-200$.

21 Kallioniemi A, Kallioniemi OP, Sudar D, Rutovitz D, Gray W, Waldman $\mathrm{F}$ et al. Comparative genomic hybridization for molecular cytogenetic analysis of solid tumors. Science $1992 \mathbf{2 5 8}$ $818-821$.

22 Agarwal SK, Schröck E, Kester MB, Burns AL, Heffess CS, Ried T et al. Comparative genomic hybridization analysis of human parathyroid tumors. Cancer Genetics and Cytogenetics $1998 \mathbf{1 0 6}$ $30-36$.

23 Palanisamy N, Imanishi Y, Rao PH, Tahara H, Chaganti RSK \& Arnold A. Novel chromosomal abnormalities identified by comparative genomic hybridization in parathyroid adenomas. Journal of Clinical Endocrinology and Metabolism 199883 1766-1770.

24 Farnebo F, Kytola S, Teh BT, Dwight T, Wong FK, Höög A et al. Alternative genetic pathways in parathyroid tumorigenesis. Journal of Clinical Endocrinology and Metabolism $1999 \mathbf{8 4}$ 3775-3780.

25 Hemmer S, Wasenius VM, Haglund C, Zhu Y, Knuutila S, Franssila K et al. Deletion of 11q23 and cyclin D1 overexpression are frequent aberrations in parathyroid adenomas. American Journal of Pathology $2001 \mathbf{1 5 8} 1355-1362$.

26 Sambrook J, Fristch EF \& Maniatis T. Molecular cloning. In A Laboratory Manual, edn 2. New York: Cold Spring Harbor Laboratory Press, 1999.

27 Lichter P \& Ried T. Molecular analysis of chromosome aberrations. In situ hybridization. Methods in Molecular Biology 1994 29 449-478.

28 Kytölä S, Farnebo F, Obara T, Isola J, Grimelius L, Farnebo LO et al. Patterns of chromosomal imbalances in parathyroid carcinomas. American Journal of Pathology 2000157 579-586.

29 Arribas B, Cristóbal E, Alcázar JA, Tardío J, Martínez-Montero JC, Polo JR et al. p53/MDM2 pathway aberrations in parathyroid tumors: p2 $1^{\mathrm{WAF}-1}$ and MDM2 are frequently overexpressed in parathyroid adenomas. Endocrine Pathology 200011 251-257.

30 Cristóbal E, Arribas B. Tardío J. Alcázar JA, Martínez-Montero JC, Carrión R et al. Analysis of the cyclin D1/p16/pRB pathway in parathyroid adenomas. Endocrine Pathology 2000 11 259-266.

31 Kjellman M, Kallioniemi OP, Karhu R, Hoog A, Farnebo LO, Auer $\mathrm{G}$ et al. Genetics aberrations in adrenocortical tumors detected using comparative genomic hybridization correlate with tumor size and malignancy. Cancer Research $1996564219-4223$.

32 Yuille MA, Coignet LJ, Abraham SM, Yaqub F, Luo L, Matutes E et al. ATM is usually rearranged in T-cell prolymphocytic leukaemia. Oncogene $199816789-796$.

33 Wang SS, Esplin ED, Li JL, Huang L, Gazdar A, Minna J et al. Alterations of the PPP2R1B gene in human lung and colon cancer. Science $1998 \mathbf{2 8 2} 284-287$.

34 Kuramochi M, Fukuhara H, Nobukuni T, Kanbe T, Maruyama T, Ghosh HP et al. TSLC1 is a tumor-suppressor gene in human non-small-cell lung cancer. Nature Genetics 200127 427-430.

Received 27 July 2001

Accepted 5 October 2001 